\title{
Myotonic dystrophy type 1 with diabetes mellitus, mixed hypogonadism and adrenal insufficiency
}

\author{
Ken Takeshima1, Hiroyuki Ariyasu', Tatsuya Ishibashi', Shintaro Kawai', Shinsuke Uraki', \\ Jinsoo Koh², Hidefumi Ito² and Takashi Akamizu'
}

${ }^{1}$ First Department of Internal Medicine and 2Department of Neurology, Wakayama Medical University, Wakayama, Japan
Correspondence should be addressed to $\mathrm{H}$ Ariyasu

Email

ariyasu@wakayama-med. ac.jp

\section{Summary}

Myotonic dystrophy type 1 (DM1) is an autosomal dominant multisystem disease affecting muscles, the eyes and the endocrine organs. Diabetes mellitus and primary hypogonadism are endocrine manifestations typically seen in patients with DM1. Abnormalities of hypothalamic-pituitary-adrenal (HPA) axis have also been reported in some DM1 patients. We present a case of DM1 with a rare combination of multiple endocrinopathies; diabetes mellitus, a combined form of primary and secondary hypogonadism, and dysfunction of the HPA axis. In the present case, diabetes mellitus was characterized by severe insulin resistance with hyperinsulinemia. Glycemic control improved after modification of insulin sensitizers, such as metformin and pioglitazone. Hypogonadism was treated with testosterone replacement therapy. Notably, body composition analysis revealed increase in muscle mass and decrease in fat mass in our patient. This implies that manifestations of hypogonadism could be hidden by symptoms of myotonic dystrophy. Our patient had no symptoms associated with adrenal deficiency, so adrenal dysfunction was carefully followed up without hydrocortisone replacement therapy. In this report, we highlight the necessity for evaluation and treatment of multiple endocrinopathies in patients with DM1.

\section{Learning points:}

- DM1 patients could be affected by a variety of multiple endocrinopathies.

- Our patients with DM1 presented rare combinations of multiple endocrinopathies; diabetes mellitus, combined form of primary and secondary hypogonadism and dysfunction of HPA axis.

- Testosterone treatment of hypogonadism in patients with DM1 could improve body composition.

- The patients with DM1 should be assessed endocrine functions and treated depending on the degree of each endocrine dysfunction.

\section{Background}

Myotonic dystrophy is an autosomal dominant multisystem disease affecting the skeletal and cardiac muscles, the eyes and the endocrine organs. Myotonic dystrophy type 1 (DM1) is the most common form, which is due to unstable trinucleotide (CTG) repeat expansion in the 3 ' untranslated region (UTR) of human dystrophia-myotonica-protein kinase (DMPK) gene (1). Toxic expanded transcripts formed by the triplet repeats accumulate in the nuclei of affected cells and sequester RNA-binding proteins, resulting in alternative splicing defects.

Insulin resistance is an endocrine abnormality associated with DM1. Muscle insulin sensitivity is 
decreased by about 70\% in patients with myotonic dystrophy compared to those of controls (1). Recently, dysregulation of alternative splicing of the insulin receptor (IR) pre-mRNA in skeletal muscle was demonstrated as one of the causes (2). Insulin sensitizers are reportedly effective for the treatment of diabetes mellitus in patients with DM1 $(3,4)$. Various mild endocrine presentations of myotonic dystrophy have also been reported (5).

Hypergonadotropic hypogonadism is a frequent complication in patients with DM1. Testicular pathology in DM1 patients shows a wide variety of tubular and interstitial damage (6). Hypogonadism is associated with increase in fat mass and loss of both muscle mass and strength. The effectiveness of testosterone therapy for hypogonadism in patients with DM1 has not yet been reported (7).

Such endocrine manifestations of DM1 could be treated as symptoms due to myopathy, and endocrine dysfunction in patients with DM1 could therefore go unnoticed.

\section{Case presentation}

A 43-year-old man was admitted to our hospital with worsening diabetes mellitus. He had a medical history of cataract surgery and catheter ablation for atrial flutter. He felt subtle weakness in his upper extremities after undergoing catheter ablation. His father also had a history of diabetes mellitus and cataracts. The patient was first diagnosed with diabetes mellitus six years prior, during preoperative medical testing for cataract surgery. Blood tests were as follows; fasting plasma blood glucose, $254 \mathrm{mg} / \mathrm{dL}$; HbA1c (NGSP), 9.9\%; plasma C-peptide (CPR), $4.0 \mathrm{ng} / \mathrm{mL}$; plasma CPR six minutes after glucagon stimulation, $8.2 \mathrm{ng} / \mathrm{mL}$ and urinary CPR, $47.2 \mu \mathrm{g} /$ day. This leads to the diagnosis of uncontrolled diabetes mellitus without insulin dependence. Insulin therapy was initiated for perioperative management of blood glucose. Surprisingly, about 60 units per day of human insulin were needed to maintain blood glucose despite preserved insulin secretion. The patient maintained HbA1c of around $7.0 \%$ with approximately 45 units/day of insulin aspart, but the cause of the severe insulin resistance remained uncertain. Glycemic control deteriorated over three years, with $\mathrm{HbA} 1 \mathrm{c}$ from $7.0 \%$ to $9.4 \%$. On admission, he was treated with 39 units of insulin aspart, sitagliptin $50 \mathrm{mg}$, voglibose $0.6 \mathrm{mg}$ and metformin $1000 \mathrm{mg}$ per day. The patient was suspected of overeating and placed on a $1600 \mathrm{kcal} /$ day $(26 \mathrm{kcal} / \mathrm{kg}$ IBW) diet, but fasting blood glucose levels remained high. Insulin secretion was not severely impaired, so insulin resistance was considered as an underlying condition the same as six years prior (Table 1). Although eight units of insulin glargine were added to reverse glucotoxicity, fasting blood glucose levels did not improve.

The patient had thin, sharp, so-called 'hatchet' facial features (Fig. 1A). Upper and lower extremities were thin with muscle atrophy. He had mild weakness in bilateral facial muscles, sternocleidomastoid and upper extremities (grip strength: right $8 \mathrm{~kg}$, left $10 \mathrm{~kg}$ ), but had no weakness

Table 1 Laboratory data on admission.

\begin{tabular}{|c|c|c|}
\hline Parameters & Values & $\begin{array}{c}\text { Reference } \\
\text { range }\end{array}$ \\
\hline \multicolumn{3}{|l|}{ Urinalysis } \\
\hline Protein & $(-)$ & \\
\hline Glucose & $(-)$ & \\
\hline Occult blood & $(-)$ & \\
\hline Ketone & $(-)$ & \\
\hline \multicolumn{3}{|l|}{ Hematology } \\
\hline 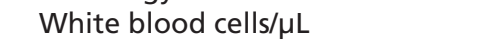 & 5555 & (3500-9800) \\
\hline Neutrophils (\%) & 70.1 & $(42.6-58.9)$ \\
\hline Lymphocytes (\%) & 19.6 & $(30.3-40.5)$ \\
\hline Eosinophils (\%) & 3.2 & $(2.4-3.7)$ \\
\hline 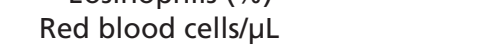 & $479 \times 10^{4}$ & $(420-550)$ \\
\hline Hemoglobin (g/dL) & 12.9 & $(13.5-17.5)$ \\
\hline Hematocrit $(\%)$ & 40.8 & $(40-52)$ \\
\hline Platelets/ $\mu \mathrm{L}$ & $15.1 \times 10^{4}$ & $(13-37)$ \\
\hline \multicolumn{3}{|l|}{ Blood chemistry } \\
\hline Total protein (g/dL) & 6.6 & $(6.7-8.1)$ \\
\hline Albumin $(\mathrm{g} / \mathrm{dL})$ & 4.0 & $(3.9-4.9)$ \\
\hline Immunoglobulin G (mg/dL) & 954 & $(870-1700)$ \\
\hline Aspartate aminotransferase (IU/L) & 23 & $(7-38)$ \\
\hline Alanine aminotransferase (IU/L) & 28 & $(4-44)$ \\
\hline Creatine kinase (IU/L) & 172 & $(60-290)$ \\
\hline Blood urea nitrogen (mg/dL) & 9.0 & $(8-20)$ \\
\hline Creatine $(\mathrm{mg} / \mathrm{dL})$ & 0.53 & $(0.53-1.02)$ \\
\hline Sodium (mEq/L) & 146 & $(135-145)$ \\
\hline Potassium (mEq/L) & 5.8 & $(3.5-5)$ \\
\hline Chloride (mEq/L) & 108 & $(98-107)$ \\
\hline Calcium (mg/dL) & 10.0 & $(8.7-11)$ \\
\hline Phosphorus (mg/dL) & 3.5 & $(2.5-4.5)$ \\
\hline Plasma osmolarity (mosmol/L) & 299 & $(275-290)$ \\
\hline Total choresterol (mg/dL) & 198 & $(130-219)$ \\
\hline Triglyceride $(\mathrm{mg} / \mathrm{dL})$ & 195 & $(30-150)$ \\
\hline Fasting plasma glucose $(\mathrm{mg} / \mathrm{dL})$ & 241 & $(70-109)$ \\
\hline HbA1c (NGSP) (\%) & 9.4 & $(4.9-6.0)$ \\
\hline Glycoalbumin (\%) & 20.4 & $(11.6-16.4)$ \\
\hline C-peptide reactivity (ng/mL) & 3.92 & $(1.1-3.3)$ \\
\hline GADAb $(\mathrm{U} / \mathrm{mL})$ & $<5.0$ & $(<5.0)$ \\
\hline \multicolumn{3}{|l|}{ Urinary chemistry } \\
\hline Creatine (mg/day) & 646 & $(500-1500)$ \\
\hline Sodium (mEq/day) & 105 & $(70-250)$ \\
\hline Potassium (mEq/day) & 20 & $(25-100)$ \\
\hline Chloride (mEq/day) & 98 & $(70-250)$ \\
\hline Urinary osmolarity (mosmol/day) & 267 & $(50-1300)$ \\
\hline
\end{tabular}

GADAb, anti-GAD antibody; NGSP, National Glycohemoglobin Standardization Program. 

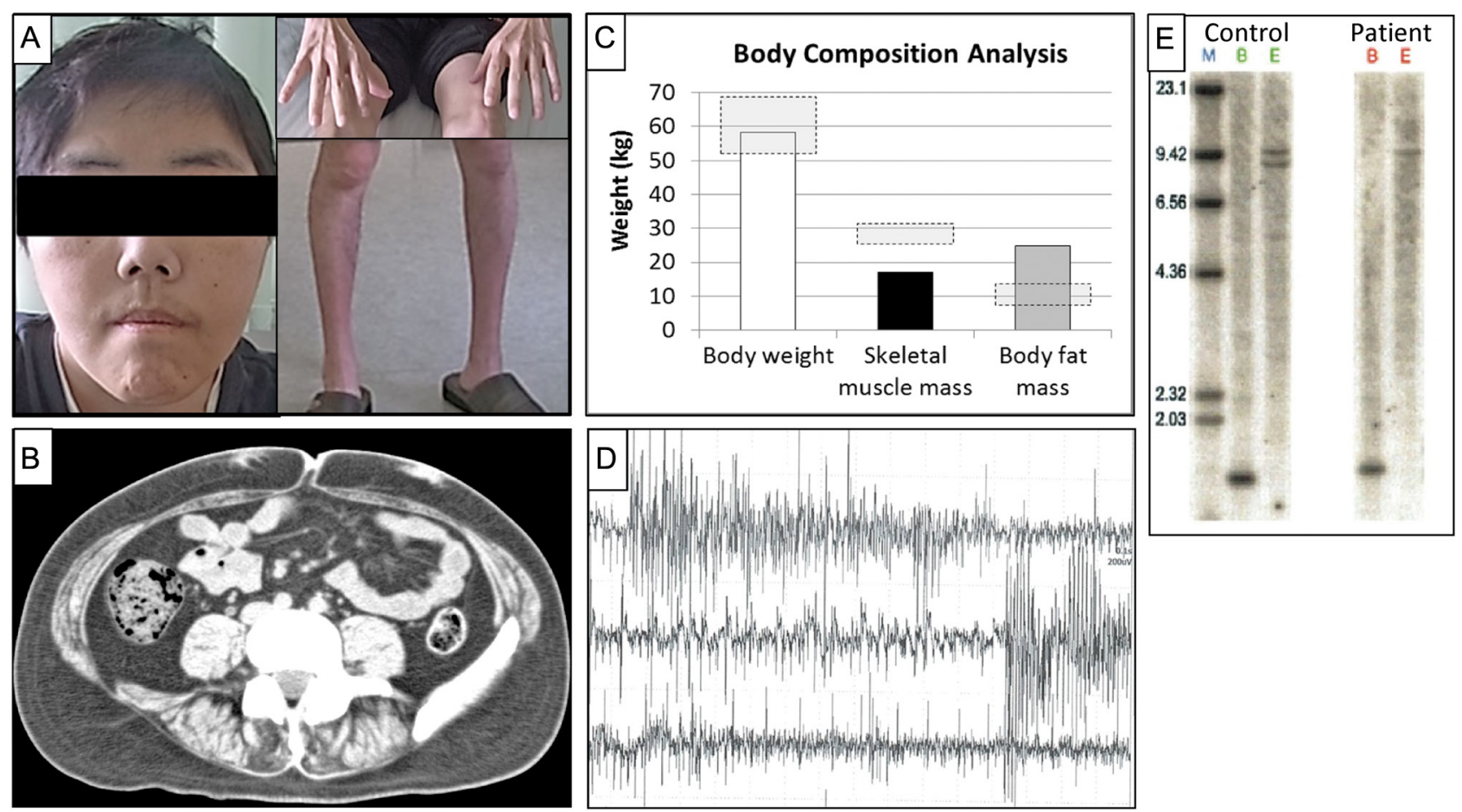

Figure 1

Clinical features and diagnosis of a patient with myotonic dystrophy type 1 (DM1). The patient had 'hatchet' facial features with atrophy of distal muscles (A). Abdominal CT and body composition analysis revealed the accumulation of fat (B and C), but skeletal muscle mass was severely decreased (C). Electromyography of his muscles showed myotonic discharge (D). Northern blot analysis confirmed about 1000 CTG repeat expansion in the $3^{\prime}$ untranslated region of human dystrophia-myotonica-protein-kinase (DMPK) gene, leading to the diagnosis of DM1 (E). M: merker, B: Bam HI, E: EcoRI.

in his lower extremities. He had grip myotonia and percussion myotonia in the thenar muscles. Deep tendon reflexes were reduced in lower extremities. Sensory examination revealed no impairment of touch, pain, temperature and vibratory sense. Body mass index (BMI) was $21.2 \mathrm{~kg} / \mathrm{m}^{2}$, but he was centrally obese, with waist circumference of $91 \mathrm{~cm}$. Abdominal CT showed excessive visceral fat (Fig. 1B). Body composition analysis (InBody720, California, USA) revealed severely decreased skeletal muscle mass in contrast to increased body fat mass (Fig. 1C).

\section{Investigation}

Mini-Mental State Examination (MMSE) score was 28 points with no decline in cognitive function.

Respiratory function tests showed decline in forced vital capacity of $2200 \mathrm{~mL}$.

Electromyogram identified myotonic discharges, raising suspicion of myotonic dystrophy (Fig. 1D). According to clinical diagnostic criteria, the patient was diagnosed as myotonic dystrophy type 1 (8). Gene analysis exhibited 1000 CTG repeats in the 3' UTR of human DMPK gene, thus confirming DM1 diagnosis (Fig. 1E).

Indirect calorimetry (AE300S, Minato Medical Science, Japan) was used to evaluate the basal metabolic rate, used to calculate resting energy expenditure (REE) as $1061 \mathrm{kcal} /$ day.

Since DM1 patients are predisposed to endocrine abnormalities, the patient's endocrine functions were evaluated. Adrenal function tests revealed the possibility of hypoadrenocorticism: adrenocorticotrophic hormone (ACTH), $12.6 \mathrm{pg} / \mathrm{mL}$; cortisol, $5.8 \mu \mathrm{g} / \mathrm{dL}$ (Table 2). Urinary free cortisol excretion was mildly decreased. Diurnal rhythm of ACTH and cortisol had disappeared, and cortisol levels were independent of corresponding ACTH levels (Fig. 2A). Corticotropin-releasing hormone (CRH) test and rapid ACTH test were performed to assess HPA axis function (Fig. 2B and C). ACTH secretion was exaggerated, although cortisol response was relatively low after $\mathrm{CRH}$ stimulation. Cortisol response was also mildly reduced after exogenous ACTH administration. Hyporesponsiveness of adrenal cortex to both endogenous and exogenous ACTH was therefore suspected. 
Table 2 Endocrinological laboratory data.

\begin{tabular}{l} 
Parameters \\
\hline ACTH $(\mathrm{pg} / \mathrm{mL})$ \\
Cortisol $(\mathrm{mg} / \mathrm{dL})$ \\
PRA $(\mathrm{ng} / \mathrm{mL} / \mathrm{H})$ \\
Aldosterone $(\mathrm{pg} / \mathrm{mL})$ \\
GH $(\mathrm{ng} / \mathrm{mL})$ \\
IGF-1 $(\mathrm{ng} / \mathrm{mL})$ \\
PRL $(\mathrm{ng} / \mathrm{mL})$ \\
LH $(\mathrm{IU} / \mathrm{mL})$ \\
FSH $(\mathrm{IU} / \mathrm{mL})$ \\
Total testosterone $(\mathrm{ng} / \mathrm{dL})$ \\
Free testosterone $(\mathrm{pg} / \mathrm{mL})$ \\
SHBG $(\mathrm{nmol} / \mathrm{L})$ \\
TSH $(\mathrm{U} / \mathrm{mL})$ \\
Free T4 $(\mathrm{ng} / \mathrm{dL})$ \\
Free T3 $(\mathrm{pg} / \mathrm{mL})$ \\
AVP $(\mathrm{pg} / \mathrm{mL})$ \\
intact PTH $(\mathrm{pg} / \mathrm{mL})$ \\
Urinary free cortisol ( $\mu \mathrm{g} /$ day) \\
Urinary free aldosterone(mg/day)
\end{tabular}

\begin{tabular}{cccc}
\cline { 1 - 1 } Values & & Reference range \\
\cline { 1 - 1 } 12.6 & & $(7.2-63.3)$ \\
5.8 & & $(2.9-19.4)$ \\
1.7 & & $(0.2-2.3)$ \\
108.0 & & $(3.6-24)$ \\
0.4 & & $(0-2.1)$ \\
30 & & $(133-368)^{\mathrm{a}}$ \\
20.9 & & $(3.6-16.3)$ \\
8.2 & & $(1.7-11.2)$ \\
40.1 & & $(2.1-18.6)$ \\
20.4 & & $(142.4-923)$ \\
10.5 & & $(4.7-21.6)$ \\
29.0 & & $(10-57)$ \\
2.26 & & $(0.35-4.94)$ \\
0.90 & & $(0.70-1.48)$ \\
2.17 & & $(1.71-3.71)$ \\
$<0.8$ & & $(\leq 4.2)$ \\
27.0 & & $(10-65)$ \\
20.0 & & $(4.3-176)$ \\
7.9 & & $(0-7.5)$ \\
\hline
\end{tabular}

aReference ranges in healthy Japanese males; bNormal value estimated by age is $13.7 \mathrm{pg} / \mathrm{mL}$.

ACTH, adrenocorticotropic hormone; FreeT3, triiodothyronine; Free T4, free thyroxine; $\mathrm{FSH}$, follicle-stimulating hormone; $\mathrm{GH}$, growth hormone; $\mathrm{LH}$, luteinizing hormone; PRA plasma renin activity; SHBG, sex hormonebinding globulin; TSH, thyroid-stimulating hormone.

Regarding hypothalamic-pituitary-gonadal (HPG) axis function, follicle-stimulating hormone (FSH) level was high, luteinizing hormone (LH) was relatively high within normal limits and testosterone levels were low, suggestive of hypergonadotropic hypogonadism (Table 2). The patient had felt loss of libido and erectile dysfunction. His testes were atrophic with testicular volume of $5 \mathrm{~mL}$ estimated by orchidometer. Human chorionic gonadotropin (hCG) stimulation test was performed to assess the testicular function. Although total testosterone levels elevated more than four times after intramuscular administration of hCG 5000 units for four days, peak value was less than the lower limit of the male reference range (Fig. 2G). Free testosterone levels after hCG stimulation were reduced. These results were compatible with primary hypogonadism. Moreover, FSH exhibited delayed, low response, while LH exhibited delayed response to the luteinizing hormone-releasing hormone (LHRH) stimulation (Fig. 2D). These were indicative of a combined form of primary and secondary hypogonadism.

Thyroid-stimulating hormone (TSH), prolactin (PRL) and growth hormone $(\mathrm{GH})$ exhibited normal responses to each provocative test, including thyrotropin-releasing hormone (TRH) and growth hormone-releasing peptide (GHRP)-2 (Fig. 2E and F).
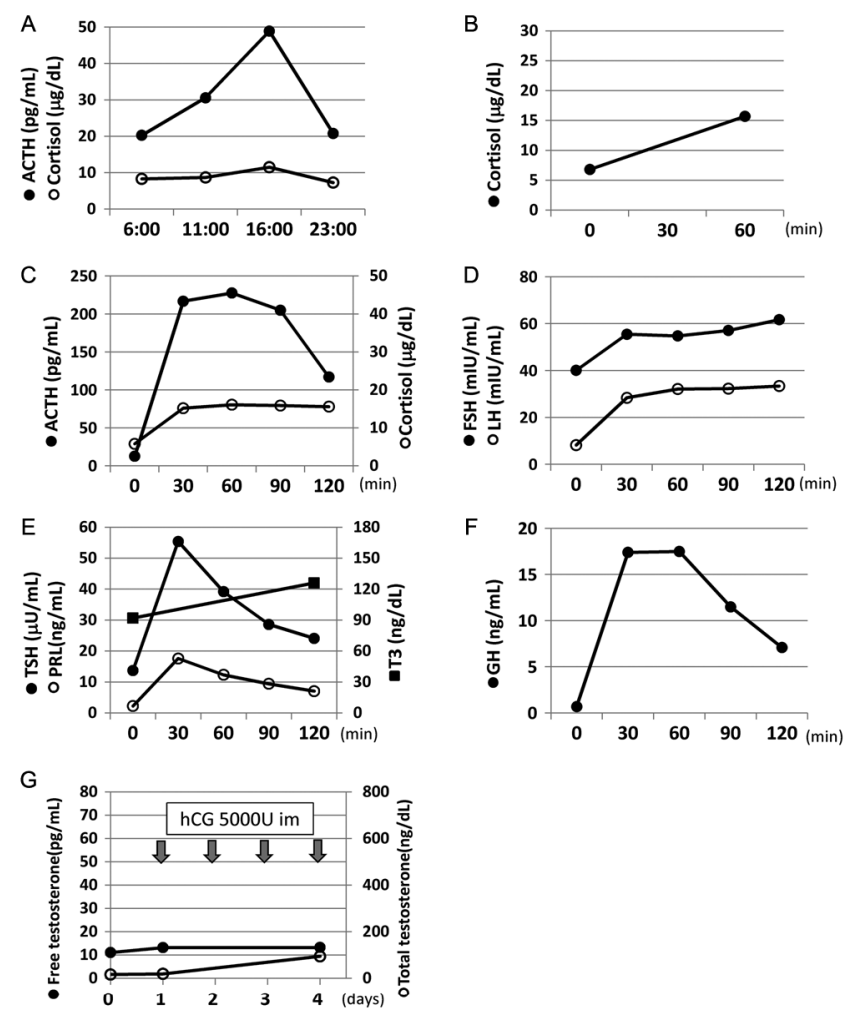

Figure 2

Pituitary endocrine tests. (A) Abnormal diurnal rhythms of ACTH and cortisol. (B) ACTH test showed relatively low cortisol response. *A serum sample taken $30 \mathrm{~min}$ after ACTH stimulation was not obtained because of problems with blood access. (C) $\mathrm{CRH}$ loading test showed hypersecretion of ACTH, but relatively low cortisol response to ACTH elevation. (D) Basal level of FSH was high. LHRH loading test showed reduced response of FSH and delayed response of LH and FSH. (E) TRH loading test showed normal responses of TSH, PRL and T3. (F) GHRP-2 loading test showed normal responses of $\mathrm{GH} . \mathrm{G}$ ) hCG loading test showed reduced response of total testosterone.

\section{Treatment}

As patients with DM1 are characterized by severe insulin resistance with hyperinsulinemia and the effectiveness of insulin sensitizers have been reported $(3,4)$, metformin was increased from $1000 \mathrm{mg}$ to $1500 \mathrm{mg}$ per day and $15 \mathrm{mg}$ of pioglitazone was added. Hypogonadism was treated with testosterone replacement therapy; testosterone enanthate at $250 \mathrm{mg}$ was administered every four weeks, with expected improvement of body composition and metabolic state. As clinical manifestations of adrenal insufficiency were absent in our patient, we decided to follow-up without hydrocortisone replacement therapy.

\section{Outcome and follow-up}

Fasting blood glucose improved approximately from 180 to $130 \mathrm{mg} / \mathrm{dL}$ two weeks after modification of insulin 
sensitizers. The patient developed body hair after six weeks of testosterone replacement therapy for hypogonadism. Moreover, body composition improved as follows: body muscle mass from 16.8 to $18.4 \mathrm{~kg}$, body fat mass from 33.1 to $32.0 \mathrm{~kg}$ and lean body mass from 32.2 to $36.3 \mathrm{~kg}$. Clinical manifestations of adrenal insufficiency, such as anorexia, hypotension and hyponatremia, did not emerge after the treatment of hypogonadism and diabetes mellitus.

Hypernatremia improved during the follow-up period. Hyperkalemia improved after the treatment of diabetes mellitus, which we consider to be attributed to a lack of insulin action.

\section{Discussion}

Our case was of DM1 with diabetes mellitus, a combined form of primary and secondary hypogonadism, and dysregulation of HPA axis.

About $10 \%$ of patients with DM1 have diabetes mellitus characterized by severe insulin resistance (1). Recently, dysregulation of alternative splicing of the insulin receptor (IR) pre-mRNA in skeletal muscle has been demonstrated as a cause (2). IR has two isoforms, IR-A and IR-B. IR-A has a higher affinity for insulin and lower signaling capacity than that of IR-B. In patients with DM1, IR-A predominates in skeletal muscle due to the dysregulation of alternative splicing, resulting in severe insulin resistance (2). Pioglitazone, an insulin sensitizer of the thiazolidinedione class, is reportedly effective in glycemic control for DM1 patients (3). Research has recently turned attention to metformin and its ability to modify alternative splicing events (4). Research also looked into the effectiveness of insulin intolerance treatment. In the present case, we could also decrease insulin requirements and improve glycemic control by modifying both insulin sensitizers.

Dysregulation of HPA axis characteristics in our patient were as follows: (i) abnormal diurnal rhythm of ACTH and cortisol, (ii) exaggerated ACTH secretion after CRH stimulation and (iii) hyporesponsiveness of adrenal cortex to ACTH stimuli. Abnormal diurnal rhythm of ACTH and cortisol in DM1 have been shown in several reports (5). DM1 patients reportedly demonstrate ACTH hypersecretion after exogenous $\mathrm{CRH}$ stimulation and endogenous $\mathrm{CRH}$ release stimulated by naloxone or fenfluramine administration (9). Accordingly, ACTH hypersecretion is attributed to the CRH stimuli. Hockings and coworkers speculated on the abnormality of dihydropyridine-insensitive $\mathrm{Ca} 2+$ transport in the corticotrophs of DM1 patients through their experiments using nifedipine and naloxone (5). They also suggested an association between DMPK and the regulation of voltagedependent $\mathrm{Ca}^{2+}$ channel as a protein kinase.

Our case also exhibited abnormal diurnal rhythm of ACTH and exaggerated ACTH secretion after CRH stimulation, indicating dysregulation of ACTH secretion, especially via CRH stimuli. Adrenal responsiveness in reported DM1 patients, on the other hand, has yielded conflicting results $(5,9)$.

DM1 patients are predisposed to hypogonadism, about eighty percent have testicular atrophy (6). Endocrine function tests usually demonstrate elevated basal gonadotropin levels and over-response of gonadotropin after gonadotropin-releasing hormone (GnRH) stimulation, symptoms consistent with primary hypogonadism. Testicular pathology of DM1 indicated various levels of testicular damage, prevailing tubular over interstitial damage (6). Our patient had elevated FSH levels and relatively high LH levels within normal limits and showed reduced testosterone response to hCG. These endocrine test results implied the presence of both tubular and interstitial damage, prevailing the former damage, as shown in previous reports. Hypogonadotropic hypogonadism in DM1 patients was also reported according to the low gonadotropin response to LHRH stimulation (10). In our patient, we confirmed delayed and low response of gonadotropins after GnRH administration, resulting in the diagnosis of combined primary and secondary hypogonadism.

Hypogonadism is associated with increase in fat mass and loss of muscle mass and strength. Hypogonadotropic hypogonadism (secondary hypogonadism) is treated by hCG therapy or selective estrogen receptor modulators (SERMs) to protect the testes. Hypergonadotropic hypogonadism (primary hypogonadism), on the other hand, is treated by testosterone replacement therapy (7). In the present case, we chose to perform testosterone replacement therapy because the patient did not wish for acquisition of fertility. Our patient notably showed increase in muscle mass and decrease in fat mass after testosterone administration. As far as we know, no previous reports have demonstrated such improvement of body composition in patients with DM1 during the treatment of hypogonadism. Such positive effects of testosterone therapy could lead to improvement of insulin resistance and diabetic control in the future.

The present case implies that manifestations associated with multiple endocrinopathies could be disguised by symptoms of myotonic dystrophy. Although patients with DM1 tend to be treated by neurologists as 
a kind of muscle disease, evaluation and treatment of endocrine dysfunctions are also necessary.

\section{Declaration of interest}

The authors declare that there is no conflict of interest that could be perceived as prejudicing the impartiality of the research reported.

\section{Funding}

This work did not receive any specific grant from any funding agency in the public, commercial, or not-for-profit sector.

\section{Patient consent}

Written informed consent was obtained from the patient for publication of this case report.

\section{Author contribution statement}

$\mathrm{K}$ Takeshima is an endocrinologist physician who followed the patient during hospitalization and wrote the first draft. $\mathrm{H}$ Ariyasu is also an endocrinologist physician and responsible for the case description. T Ishibashi, S Kawai and S Uraki are endocrinologist physicians who followed the patient during hospitalization. Jinsoo Koh is a neurologist physician and Hidefumi Ito is the Director of the Department of Neurology who also followed the patient during hospitalization. T Akamizu is Director of the First Department of Medicine and revised and approved the final draft.

\section{References}

1 Harper PS. Myotonic dystrophy-the clinical picture. In Myotonic Dystrophy, pp 17-46, ed 3rd. London: WB Saunders, 2001.

2 Savkur RS, Philips AV \& Cooper TA. Aberrant regulation of insulin receptor alternative splicing is associated with insulin resistance in myotonic dystrophy. Nature Genetics 200129 40-47. (https://doi. org/10.1038/ng704)

3 Abe H, Mita T, Kudo K, Funayama T, Tokoro M, Kaga H, Ikeda F, Kanazawa A, Hirose T, Kawamori R, et al. Dramatic improvement of blood glucose control after pioglitazone treatment in poorly controlled over-weight diabetic patients with myotonic dystrophy. Endocrine Journal 200956 911-913. (https://doi.org/10.1507/endocrj. K09E-122)

4 Laustriat D, Gide J, Barrault L, Chautard E, Benoit C, Auboeuf D, Boland A, Battail C, Artiguenave F, Deleuze JF, et al. In vitro and in vivo modulation of alternative splicing by the biguanide metformin. Molecular Therapy: Nucleic Acids 20154 e262. (https://doi. org/10.1038/mtna.2015.35)

5 Hockings GI, Grice JE, Crosbie GV, Walters MM \& Jackson RV. Altered hypothalamic-pituitary-adrenal axis responsiveness in myotonic dystrophy: in vivo evidence for abnormal dihydropyridine-insensitive calcium transport. Journal of Clinical Endocrinology and Metabolism 199376 1433-1438. (https://doi. org/10.1210/jcem.76.6)

6 Vazquez JA, Pinies JA, Martul P, De los Rios A, Gatzambide S \& Busturia MA. Hypothalamic-pituitary-testicular function in 70 patients with myotonic dystrophy. Journal of Endocrinological Investigation 199013 375-379. (https://doi.org/10.1007/BF03350681)

7 Bhasin S, Cunningham GR, Hayes FJ, Matsumoto AM, Snyder PJ, Swerdloff RS, Montori VM \& Task Force, Endocrine Society. Testosterone therapy in men with androgen deficiency syndromes: an Endocrine Society clinical practice guideline. Journal of Clinical Endocrinology and Metabolism 201095 2536-2559. (https://doi. org/10.1210/jc.2009-2354)

8 Tetsuro M. Myotonic Dystrophy. Journal of the Japan Diabetes Society 201558 532-534. (https://doi.org/10.11213/tonyobyo.58.532)

9 Buyalos RP, Jackson RV, Grice GI, Hockings GI, Torpy DJ, Fox LM, Boots LR \& Azziz R. Androgen response to hypothalamic-pituitaryadrenal stimulation with naloxone in women with myotonic muscular dystrophy. Journal of Clinical Endocrinology and Metabolism 199883 3219-3224. (https://doi.org/10.1210/jcem.83.9.5078)

10 Febres F, Scaglia H, Lisker R, Espinosa J, Morato T, Shkurovich M \& Përez-Palacios G. Hypothalamic-pituitary-gonadal function in patients with myotonic dystrophy. Journal of Clinical Endocrinology and Metabolism 197541 833-840. (https://doi.org/10.1210/jcem41-5-833)

Received in final form 6 December 2017

Accepted 15 December 2017 